\title{
SISTEMA NACIONAL DE COMÉRCIO JUSTO E SOLIDÁRIO
}

\author{
BRAZILIAN SYSTEM OF FAIR TRADE AND SOLIDARITY
}

Danielle Mendes Thame Denny

Doutoranda pela Universidade Católica de Santos, com bolsa da Coordenação de Aperfeiçoamento de Pessoal de Nível Superior. Mestre em Comunicação na Contemporaneidade, pela Faculdade Cásper Líbero. Com especializações em: Diplomacia Econômica, pela Universidade Estadual de Campinas; Direito Tributário, pela Pontifícia Universidade Católica de São Paulo; e Política pela Escola de Governo da Universidade de São Paulo. Bacharel em Direito pela Pontifícia Universidade Católica de São Paulo.

Professora universitária na Fundação Armando Álvares Penteado e na Universidade

Paulista. Integra três grupos de pesquisa na Universidade Católica de Santos: Energia e Meio Ambiente; Direito Econômico Internacional e Meio Ambiente; e Direito Marítimo. Membro da Comissão de Mídia e Entretenimento do Instituto dos Advogados de São Paulo e da Ordem dos Advogados de São Paulo. E-mail: daniellethame@uol.com.br

Rodrigo Farias Julião

Doutorando em Direito Ambiental Internacional pela Universidade Católica de Santos. Possui graduação em CIENCIAS JURÍDICAS E SOCIAIS pela Universidade Metropolitana de Santos (1999) e mestrado em Direito pela Universidade Metropolitana de Santos (2008). Professor na Universidade Católica de Santos - UNISANTOS na disciplina de Direito Processual do Trabalho e PráticaTrabalhista.Tem experiência na área de Direito, com ênfase em Direito Civil, Direito do Trabalho, Empresarial e Constitucional. Autor do Livro Ética e Estatuto da Advocacia da Editora Atlas - 2a. Edição. Co-autor do Livro Exame da OAB da Editora Saraiva. Co-autor da Revista Jurídica da Faculade de Direito da Faculadde de Ribeirão Preto. Atual Presidente da Ordem dos Advogados do Brasil - Subseção de Santos. E-mail: juliao@globo.com

Recebido em: 17/10/2016

Aprovado em: 13/02/2017

Doi: $10.5585 /$ rdb.v16i7.509

RESUMO: O decreto que instituiu o Sistema Nacional do Comércio Justo e Solidário, atribui sua gestão ao Ministério do Trabalho e Emprego e define os organismos de acreditação e de avaliação da conformidade. Nesse contexto, normas técnicas e padrões privados passam a ter especial relevância. O estudo dessa normatização difusa, transfronteiriça e, muitas vezes, privada é a proposta do presente artigo, na linha de pesquisa Direito, Economia e Desenvolvimento Sustentável. A metodologia escolhida foi a dialógica, buscando a contraposição interdisciplinar necessária para construir convenções úteis. As técnicas de delineamento utilizadas foram pesquisa bibliográfica, documental e legislativa.

Palavras-chave: Sistema Nacional do Comércio Justo e Solidário, Certificação, Padrões Privados

ABSTRACT: The decree establishing the Brazilian System of Fair Trade and Solidarity, assigns its management to the Labor Office and defines the accreditation bodies and conformity assessment rules. In this subject, therefore, technical standards and private standards gain special 
relevance. The study of this paper is about the diffuse, transnational and often private regulation, in accordance with the research line Law, Economy and Sustainable Development. The methodology chosen was the dialogic, which articulates the necessary interdisciplinary opposition to build useful conventions. The design techniques used were bibliographical, documentary and legislative research.

Keywords: National System of Fair and Ethical Trade, Accreditation, Private Standards

SUMÁRIO: Introdução; Desenvolvimento: Erradicação da pobreza de Objetivos do Desenvolvimento Sustentável, Mecanismos de incentivo e padrões privados; Normas privadas voluntárias; O caso do Sistema de Comércio Justo e Solidário no Brasil; Conclusões e Referências.

\section{INTRODUÇÃO}

O Decreto Presidencial de n. 7.358, de 17 de novembro de 2010, que instituiu o Sistema Nacional do Comércio Justo e Solidário (SCJS), e em especial o art. 3o, parágrafo único, coloca como atribuição do Ministério do Trabalho e Emprego: "a gestão do SCJS, os seus princípios e os critérios de reconhecimento de práticas de comércio justo e solidário e que os mesmos serão disciplinados em ato normativo do Ministério do Trabalho e Emprego (MTE)". Além disso, define, entre outros, empreendimentos econômicos solidários, organismos de acreditação e organismos de avaliação de conformidade.

A Portaria Ministerial n. 30, de 20 de março de 2006 do MTE, instituiu o Sistema Nacional de Informação em Economia Solidária - SIES e caracteriza o que é um Empreendimento Econômico Solidário (EES), e uma Entidade de Apoio a Fomento de economia solidária (EAF). A Portaria Ministerial n. 2060 de 30 de dezembro de 2014 do MTE, publicada em 08 de janeiro de 2015 no Diário Oficial, traz a mais recente definição do SCJS como um "sistema ordenado de parâmetros que visa promover as práticas de relações comerciais mais justas e solidárias, articulando e integrando os empreendimentos econômicos solidários e seus parceiros colaboradores em todo o território brasileiro".

Essas matizes regulatórias públicas nacionais, refletem princípios e conformidades propostos por duas grandes organizações não governamentais internacionais: a Fairtrade International (FLO) e a World Fair Trade Organization (WFTO). Com isso identifica-se o êxito que o trabalho de regulação transnacional, promovido por essas organizações, acaba conseguindo dentro dos ordenamentos jurídicos nacionais. Certamente há outras narrativas e outras organizações envolvidas com a temática, mas essas duas tem sido as reconhecidas como as melhores e portanto seus padrões e certificações acabam sendo os basilares para uma possível harmonização internacional.

O comércio justo e solidário é um conceito complexo que prevê dimensões múltiplas (social, econômica, ambiental, política). O fracasso do comércio convencional unidimensional perseguindo apenas o lucro e no máximo contido à força por lutas sociais, impõe à contemporaneidade criar trabalhos alternativos, meios de subsistência sustentáveis e oportunidades de desenvolvimento para as pessoas em diversos níveis. Cria-se, portanto uma agenda internacional para fomentar a ação conjunta, colaborativa e orientada para um mundo fraterno, socialmente includente e ambientalmente responsável. Por meio de uma prática de consecução de justiça comercial e trabalhista que faz do trabalho e do consumo um ato político de inclusão social.

O SCJS, gerido pelo MTE, e articulado aos organismos internacionais de acreditação e de avaliação de conformidade faz parte de um movimento global de 'fair trade' que compartilha da visão de um mundo em que a justiça e o desenvolvimento sustentável constituem o centro das 
estruturas e práticas comerciais, de modo que todos, através de seu trabalho, possam manter uma vida digna para desenvolver todo seu potencial humano.

Por razões históricas e política o funcionamento do SCJS no Brasil extrapola o contexto de padrões privados e de certificação, incorporando no comércio justo e solidário CJS organizações, inclusive públicas, ligadas à Economia Solidária, fazendo parte como agente político de uma agenda de formação de uma política pública mais ampla para promover os Empreendimentos Econômicos e Solidários.

Sendo assim, o objetivo do presente trabalho foi o estudo da normatização difusa, transfronteiriça e, muitas vezes, privada, sobre comércio justo e solidário, na linha de pesquisa Direito, Economia e Desenvolvimento Sustentável. A metodologia escolhida foi a dialógica, buscando a contraposição interdisciplinar necessária para construir convenções úteis. As técnicas de delineamento utilizadas foram pesquisa bibliográfica, documental e legislativa

\section{DESENVOLVIMENTO: ERRADICAÇÃO DA POBREZA DE OBJETIVOS DO DESENVOLVIMENTO SUSTENTÁVEL}

A linha de pesquisa Direito, Economia e Desenvolvimento Sustentável, traz em si um dos temas mais complexos do Direito: como articular economia e sustentabilidade? Na teoria parece simples, basta coordenar esforços para uma economia lucrativa, socialmente inclusiva e com respeito ao meio ambiente. Na prática, contudo, os desafios são os mais pervasivos. Como um maestro de orquestra sinfônica, há de ser conseguida uma harmonia sutil e instável, entre os diversos interesses envolvidos nessas relações. A dificuldade aumenta ainda mais porque o contexto internacional não pode ser excluído ou ignorado.

Há portanto uma diversidade de assuntos, agentes e políticas que precisam ser levados em conta, causando uma impressão de dispersão, falta de articulação, diversidade teórica e técnica, impossível de ser superada, quando na verdade, é desafiante mas possível, demanda sistematização abrangente e articulação dinâmica de interesses para conseguir propostas criativas de solução para problemas comuns. De qualquer forma, a economia socioambientalmente inclusiva não pode ser confinada dentro dos limites de um ramo do Direito, é interdisciplinar por natureza. Problemas complexos demandam soluções igualmente complexas. Essa economia sustentável precisa, portanto, ser perseguida com iniciativas complexas.

Nesse sentido, a erradicação da pobreza é o maior desafio global que o mundo enfrenta hoje e trata-se de um requisito indispensável para desenvolvimento sustentável, conforme a Agenda 2030, que instituiu os objetivos do desenvolvimento (ODS) é logo a primeira das dezessete metas identificadas. O objetivo segundo é: "acabar com a fome, alcançar a segurança alimentar e melhoria da nutrição e promover a agricultura sustentável”. (Agenda 2030, 2015, p.17)

Esses objetivos, contudo não podem ser alcançados se não houver uma cooperação entre setor privado e público, entre sociedade civil, governos e empresas. A iniciativa privada tem o potencial de contribuir com: financiamento de projetos, (ii) a transferência de tecnologia e também (iii) governança ambiental. Porém, precisa ser fiscalizada para não cometer abusos, agravando ainda mais a situação de desigualdade. O desafio, portanto, é além da introdução de certos controles sobre as atividades do sector privado (inclusão de códigos de ética corporativos ou mecanismos de controle e responsabilização), criar formas de fomentar o investimento privado em projetos sociambientalmente responsáveis, como tirar vantagem do capital para promover o desenvolvimento sustentável. 
A contribuição do sector privado é particularmente importante no que diz respeito (i) ao financiamento de projetos, (ii) à transferência de tecnologia e (iii) à governança ambiental. "(DUPUY e VINUALES, 2015, p. 33) ${ }^{1}$

Com relação às questões socioambientais, a natureza internacional e transdisciplinar da questão faz com que as dificuldades dos métodos tradicionais de criação do direito internacional sejam bastante impactantes nessa área.

Esse impacto está nas raízes de três importantes características do direito ambiental internacional: (i) a prevalência de tratados como fonte de direito ambiental internacional, (ii) o uso freqüente de instrumentos de soft law55 e (iii) o desenvolvimento crescente de um «Droit dérivé» ou o direito administrativo do ambiente sob a forma de decisões adoptadas pelas COP estabelecidas pelos MEA. (DUPUY e VINUALES, 2015, p. 33) ${ }^{2}$

As relações entre a sociedade civil e setor privado, principalmente no que concerne a proteção ambiental são complexas, mas soluções nessa área só podem ser alcançadas com a cooperação e muitas vezes dependendo da iniciativa do sector privado, as empresas têm de ser parte da solução não do problema. Essa mudança de paradigma vai muito além de propor a disseminação de códigos de conduta ou relatórios de responsabilidade socioambiental corporativa ou de defender ação mais efetiva dos departamentos de compliance com uso de mecanismos de prestação de contas. O desafio é orientar o interesse privado em projetos pró-ambiente (DUPUY e VINUALES, 2015, p. 34) seja por parcerias público privado, ou por incentivos diretos via intervenção pública no domínio econômico

\section{MECANISMOS DE INCENTIVO E PADRÕES PRIVADOS}

Os mecanismos de incentivo para que o setor privado respeite as normas ambientais têm dois objetivos principais: aumentar a eficiência das cadeias produtivas (reduzindo o custo da conformidade entre os diversos produtos e serviços) e compensar a falta de capacidade técnica e financeira dos produtores em alguns países (isso se verifica por meio de mecanismos de assistência). Nesse sentido, os padrões transnacionais podem promover o comércio, em muitos aspectos, estabelecendo normas acordadas e aplicadas por governos ou organizações privadas, incluindo organizações não governamentais, associações comerciais e grandes empresas.

Existem muitos argumentos a favor e contra os padrões privados, mas uma coisa é certa, eles se tornaram uma realidade generalizada é inevitável tratar deles ao analisar o comércio internacional atual e as cadeias globais de valor. O ideal seria que a Organização Mundial do Comércio $(\mathrm{OMC})$ deixasse de ser reticente com relação à temática e passasse a atuar como árbitro final e como órgão meta regulador, estabelecendo as normas que devem ser seguidas para a elaboração de padrões privados.

O desafio é maximizar os efeitos positivos e minimizar os negativos. Padrões privados podem prestar para garantir a segurança de produtos e estabelecer a homogeneidade reduzindo custos. No entanto, podem levantar uma série de preocupações relacionadas à responsabilidade e à legitimidade de quem os define, bem como ter efeito potencialmente impeditivo do comércio.

\footnotetext{
${ }^{1}$ Tradução livre feita pelos autores de "The contribution of the private sector is particularly important in connection with (i) project financing, (ii) technology transfer and also (iii) environmental governance. established by MEAs."

${ }^{2}$ Tradução livre feita pelos autores de "Such impact lies at the roots of three important features of international environmental law: (i) the prevalence of treaties as a source of international environmental law, (ii) the frequent use of instruments of soft law55 and (iii) the increasing development of a 'droit dérivé' or administrative law of the environment in the form of decisions adopted by the COPs established by MEAs."
} 
Padrões internacionais podem promover o comércio de muitas maneira e acima de tudo por aprimorar a segurança dos produtos. Esses padrões podem ser exigidos por governos ou pela iniciativa privada (...) e têm se disseminado (...) tendo em vista as limitações de capacidade nos países em desenvolvimento é importante analisarmos os padrões privados do ponto de vista do desenvolvimento (...) também importante entender a proliferação deles e a possibilidade da Organização Mundial do Comércio exercer a função de árbitro para os padrões que afetem o comércio internacional. A fim de maximizar os efeitos positivos e minimizar os negativos. (UN Forum on Sustainability Standards, 2013).

A característica primordial dos padrões privados é serem orientados para o mercado, a fim de garantir e alguns produtos são seguros e homogêneos, essa garantia no longo prazo otimiza os processos, diminui perdas e reduz custos. Mas a disseminação dessa forma de autoregulação do mercado pelo próprio mercado suscita uma série de possíveis preocupações principalmente a respeito da governança desse modelo, como por exemplo quem teria legitimidade para estabelecer os critérios e de quem é a responsabilidade por fiscalizar se está ou não sendo cumprido. O Forum da ONU sobre padrões de sustentabilidade relacionou alguns dos problemas que podem distorcer o comércio:

1. Falta de harmonização e equivalência em normas semelhantes, incluindo custos de conformidade, uma vez que existem múltiplos padrões para um único produto

2. A marginalização das pequenas empresas e dos países em desenvolvimento e menos desenvolvidos devido a padrões complexos, rigorosos e multidimensionais

3. A noção de que as normas privadas comprometem a estrutura dos Acordos da OMC sobre Barreiras Técnicas ao Comércio e sobre Medidas Sanitárias e Fitossanitárias

4. O risco de que as normas privadas sejam medidas dissimuladas e arbitrárias que minem o livre comércio

5. A multiplicação de normas privadas que possam pôr em risco os seus objetivos de sustentabilidade e criar confusão para os produtores e consumidores 6. Não abordar os riscos na composição das normas privadas, uma vez que muitas das normas não são baseadas na ciência

7. Os efeitos de muitas normas privadas que fazem parte das cadeias de fornecimento globais, nas políticas e prioridades nacionais.

(UN Forum on Sustainability Standards, 2013).

\footnotetext{
${ }^{3}$ Tradução livre feita pelos autores de "At their best, private standards are market-driven efforts to ensure product safety and to establish homogeneity to reduce costs. However, private standards raise a number of concerns that in one way or another relate to the accountability and legitimacy of those who set them, as well as their potentially impeding effect on trade:

1. Lack of harmonization and equivalence on similar standards, including compliance costs, since there are multiple standards for a single product

2. Marginalization of small companies and developing and least developed countries due to complex, rigorous and multidimensional standards

3. The notion that private standards undermine the structure of the WTO Agreements on Technical Barriers to Trade (TBT) and Sanitary and Phytosanitary Measures (SPS)

4. The risk that private standards are disguised and arbitrary measures that undermine free trade

5. The multiplication of private standards that may put at risk their sustainability objectives and create confusion for producers and consumers

6. Failure to address risks in the composition of private standards, since many of the standards are not science- based

7. The effects of many private standards that are part of global supply chains, on national policies and priorities."
}

Revista de Direito Brasileira | São Paulo, SP | v. 16 | n. 7 | p. 211 - 224 | Jan./Abr. 2017 
Conforme a FLO, os padrões para certificação do comércio justo e solidário são elaborados para apoiar principalmente o desenvolvimento sustentável de organizações de pequenos produtores e trabalhadores de países em desenvolvimento, sobretudo os da agricultura nos países pobres.

Os seus principais objetivos são:

(i) assegurar que os produtores recebam preços que cubram os custos de produção sustentável;

(ii) prover o pagamento de um valor adicional 'Fairtrade Premium' para ser investido em projetos que visem à melhoria do desenvolvimento econômico, social e ambiental;

(iii) permitir pré-financiamento a produtores que precisem;

(iv) facilitar parcerias comerciais de longo prazo e permitir maior controle dos produtores sobre o processo comercial; e

(v) estabelecer critérios centrais e de desenvolvimento claros para assegurar que as condições de produção e comercialização de todos os produtos certificados de Fairtrade sejam responsáveis social e ambientalmente e economicamente justos. (PARK, 2015, p.69)

Em linhas gerais são estabelecidos requisitos que os produtores e comerciantes devem satisfazer para poderem obter a certificação 'Fairtrade' para um produto, a lista de conformidades e extensa e detalhada por tipo de produto e de organização. Assim, por exemplo, o procedimento para o açúcar é diferente do café, e o do pequeno produtor se distingue também do das outras formas de organização do trabalho.

O processo de elaboração dos padrões é detalhado no site do Fairtrade International, mas não cabe sua reprodução neste suscinto trabalho, estando previsto um processo com ampla consulta aos stakeholders. Já o processo de certificação, levado a cabo pela FLO prevê que os candidatos submetam seu pedido de apreciação para serem certificados. Para depois serem submetidos a uma auditoria inicial, se todos os critérios de conformidade válidos forem cumpridos há aprovação. Caso seja recusada, o pleiteante pode, após realizar mudanças para atingir a conformidade aos critérios da FLO, candidatar-se novamente e é assegurado o contraditório no processo, dessa forma, os candidatos podem contestar, pedir revisão da análise ou esclarecimentos.

Padrões privados, como esses da FLO, parecem ter três papéis simultaneamente: substituir regulação pública inadequada, ser uma resposta a uma regulamentação cada vez mais rigorosa em áreas como a ambiental por exemplo, e ser uma forma para superar as regulamentações públicas e fornecer bases sistematizadas para a diferenciação dos produtos. Em grande parte a escalada de desenvolvimento de normas privadas é uma resposta às medidas regulatórias implementadas pela Europa. Porém fazem parte de tendências mais amplas de coordenação da cadeia de valor no contexto das mudanças em curso nos controles regulatórios, da demanda do consumidor, e da governança multistakeholder e pragmática que vem sendo necessária no âmbito do comércio internacional.

Os padrões privados são uma de quatro combinações possíveis no esquema de regulação público / privado e obrigatória / voluntário: a) padrões públicos obrigatórios: denominados regulamentos; b) normas públicas voluntárias: padrões que são criados por organismos públicos, mas cuja adoção é voluntária; c) normas desenvolvidos pelo setor privado que são, em seguida, 
tornadas obrigatórias pelo poder público e normas privadas voluntárias: desenvolvidos e aprovados por organismos privados.

Isto leva a quatro combinações possíveis de público/privado e obrigatório/voluntário:

. Padrões públicos, obrigatórios: mais precisamente denominados "regulamentos".

. Padrões públicos voluntários: padrões criados por órgãos públicos, mas cuja adoção é voluntária. (...) leis opcionais. No sector agro-alimentar, o «Label Rouge» desenvolvido pelo governo francês é um exemplo

- Padrões privados legalmente exigidos: padrões desenvolvidos pelo setor privado, que são então tornados obrigatórios por órgãos públicos.

. Padrões privados voluntários: padrões desenvolvidos e adotados por entidades privadas(HENSON e HUMPHREY, 2009, p. 1630) ${ }^{4}$

\section{NORMAS PRIVADAS VOLUNTÁRIAS}

No caso da regulação do comércio justo o processo partiu exclusivamente do setor privado, apesar de as organizações buscarem atuar também junto ao setor público nacional e internacional para promover a maior adesão. Normas privadas voluntárias têm cinco funções a desempenhar: a) formular os procedimentos operacionais de um padrão; b) decidir sobre a adoção ou não de um padrão; c) implementar a regra prevista a partir de procedimentos de adequação, d) avaliação de conformidade para verificar se aqueles que afirmam cumprir a norma podem fornecer provas documentais para comprovar o cumprimento das normas; e) certificação, recomendação de medidas corretivas ou descreditação caso não haja conformidade.

(Normas voluntárias privadas) têm cinco funções a serem desempenhadas:

. Definição de padrões: A introdução e operacionalização de uma norma através da formulação de regras e procedimentos escritos.

. Adoção: A decisão de uma entidade de adotar a norma, que pode ou não ser a mesma entidade que desenvolve a norma.

- Implementação: A implementação da regra através dos procedimentos de aplicação por outra entidade.

- Avaliação da conformidade: Procedimentos para verificar que aqueles que alegam cumprir a norma podem fornecer provas documentadas para mostrar que este é o caso. Isso geralmente inclui a especificação de entidades certificadoras terceirizadas credenciadas que são responsáveis pela avaliação da conformidade. . Aplicação: Procedimentos para responder pelo descumprimento e sanções para retirar o reconhecimento se não forem tomadas medidas corretivas. (HENSON e HUMPHREY, 2009, p. 1631)

\footnotetext{
4 Tradução livre feita pelos autores de "This leads to four possible combinations of public/private and mandatory/voluntary:

. Public, mandatory standards: more accurately termed 'regulations'.

. Public voluntary standards: standards that are created by public bodies but whose adoption is voluntary. Brunsson and Jacobsson (2000) refer to these as 'optional laws'. In the agri-food sector, the 'Label Rouge' developed by the French government is an example (for a study of the Label Rouge scheme, see Fanatico and Born, 2002).

. Legally-mandated private standards: standards developed by the private sector which are then made mandatory by public bodies.

. Voluntary private standards: standards developed and adopted by private bodies.”

${ }^{5}$ Tradução livre feita pelos autores de " (Voluntary private standards have) five functions to be performed:

. Standard setting: The introduction and operationalisation of a standard through the formulation of written rules and procedures.
}

Revista de Direito Brasileira | São Paulo, SP | v. 16 | n. 7 | p. 211 - 224 | Jan./Abr. 2017 
Além disso, existe uma notória divisão temática: a) padrões relacionados a segurança alimentar; b) regulações exigindo o cumprimento de normas ambientais e sociais; c) padrões técnicos e de qualidade; e, por último, d) quadro normativos meta regulatórios, a respeito de melhores práticas para serem elaboradas as normas privadas voluntárias.

(...)Há pelo menos quatro tipos de regimes de regulamentação: i) normas privadas de segurança alimentar; Ii) "regulamentação civil" ou códigos e normas privados para controlar os aspectos ambientais e sociais das operações comerciais; Iii) normas técnicas e de qualidade; e iv) quadros meta-regulatórios privados (...) "Regulamentação civil" é o termo que tem sido utilizado para definir a estrutura da regulação privada que lida com os impactos sociais e ambientais das operações da empresa(THORSTENSEN e VIEIRA, 2015, p. 5) ${ }^{6}$

Esses esforços normativos buscam sistematizar a análise dos produtos e fornecedores. Podem servir para a facilitação do comércio e também contribuir com a efetividade da governança global multistakeholder. Haja vista que até organismos de fomento como Banco Mundial precisam qualificar seus investimentos seguindo algum tipo de padrão e praticar a 'accountability'.

\begin{abstract}
Algumas organizações, como o Banco Mundial ou bancos regionais de desenvolvimento, devem cumprir as normas internas (incluindo as normas ambientais) na condução de suas atividades. Eles devem assegurar que os projetos que financiam estão de acordo com essas normas e uma série de procedimentos abertos à sociedade civil (por exemplo, o que foi apresentado ao Painel de Inspeção do Banco Mundial) para revisar o cumprimento dessas normas. Este tipo de revisão da conformidade deve ser distinto das formas tradicionais de "responsabilidade". Os termos usados neste sentido são "accountability", bem como para os procedimentos estabelecidos para rever o cumprimento dos direitos humanos ou tratados ambientais ou com as normas de responsabilidade social corporativa. (DUPUY e VINUALES, 2015, p. 253) ${ }^{7}$
\end{abstract}

\footnotetext{
. Adoption: A decision by an entity to adopt the standard, which may or may not be the same entity that develops the standard.

. Implementation: The implementation of the rule through the application procedures by another entity.

- Conformity assessment: Procedures to verify that those claiming to comply with the standard can provide documented evidence to show that this is the case. This often includes the specification of accredited third-party certifying bodies that are responsible for assessing compliance.

. Enforcement: Procedures to respond to non-compliance and sanctions to withdraw recognition if corrective action is not taken.

${ }^{6}$ Tradução livre feita pelos autores de "at least four types of regulatory schemes can be distinguished: i) private food safety standards; ii) 'civil regulation' or private codes and standards to control environmental and social aspects of business operations; iii) technical and quality standards; and iv) private meta-regulatory frameworks (...) ${ }^{\circ} \mathrm{Civil}$ regulation' is the term that has been used to define the structure of private regulation that deals with social and environmental impacts of business operations

${ }^{7}$ Tradução livre feita pelos autores de "We will only note in this regard that international organisations are subject to primary norms that may trigger a system of international responsibility. In addition, some organisations, such as the World Bank or regional development banks, must comply with internal standards (including environmental standards) in the conduct of their activities. They must ensure that the projects they finance comply with these standards and a number of procedures open to civil society (e.g. the one before the World Bank Inspection Panel) have been set up to review compliance with such standards. This type of compliance review must be distinguished from traditional forms of 'responsibility' and 'liability'. The terms used in this regard are 'accountability', much like for procedures established to review compliance with human rights or environmental treaties or with corporate social responsibility standards
}

Revista de Direito Brasileira | São Paulo, SP | v. 16 | n. 7 | p.211 - 224 | Jan./Abr. 2017 


\section{O CASO DO SISTEMA DE COMÉRCIO JUSTO E SOLIDÁRIO NO BRASIL}

A criação do SCJS no Brasil contou desde o início com o envolvimento de organizações governamentais e da sociedade civil. A entidade criada em 2001 para ser ponto focal desse processo foi a Faces Brasil, composta por diversas entidades, do terceiro setor: Fase Nacional, Kairós, FES, Visão Mundial, Instituto Sere, Onda Solidária, IMAFLORA; entre os produtores, organizações e redes nacionais, representantes de trabalhadores rurais e urbanos: UNISOL, UNICAFES, RBSES, FBES, Rede Ecovida, ADS-CUT; entidades governamentais: SENAES MTE, SAF - MDA; sistema nacional de fomento: SEBRAE - Nacional. (FACES, 2008, p. 2)

Dessa forma, o Faces não foi, um mero agente de internalização de normas, foi muito além do transplante de práticas transnacionais, promoveu desde o início a construção da ideia de comércio justo, "abrasileirada", com interlocutores já previamente envolvidos em pautas e movimentos específicos condizentes com a temática do comércio justo. O Fórum Brasileiro de Economia Solidária pode ser apontado como fruto do contexto histórico do qual também decorreu a organização do I Fórum Social Mundial (I FSM), com a participação de 16 mil pessoas de 117 países, nos dias 25 a 30 de janeiro de 2001, em Porto Alegre, Rio Grande do Sul.

Assim, o processo de importação das normas de comércio justo, dos seus princípios gerais e dos padrões de certificação foi modulado por contextos, demandas e atores específicos como (i) a ascensão de Luiz Inácio Lula da Silva à presidência, trazendo as pautas do Partido dos Trabalhadores para a agenda do Planalto; (ii) as plenárias realizadas sobre a Economia Solidária; e (iii) as preocupações sociais com viabilizar a produção e canais de comercialização dos produtos da economia solidária e familiar.

Disso decorreu uma alteração significativa dos contornos ideológicos o processo internalização das normas. No âmbito transnacional baseava-se em soluções de mercado para a erradicação de pobreza, inserido, portanto, na lógica capitalista. Já no âmbito nacional, o processo adotou um referencial ideológico altermundialista, ligado ao socialismo e a meios alternativos ao capitalismo e à globalização econômica. Outro fator peculiar foi a presença do Estado na construção do conceito "comércio justo" brasileiro, reconhecendo a iniciativa transnacional que ocorreu a partir de atores privados, mas prevendo regulação pública dessa comercialização justa.

Para o Estado estar presente, foi criada a Comissão Gestora Nacional (CGN) do SCJS, que gerencia serve de autoridade do sistema. Assim, além de regulador, o Estado consegue fomentar o comércio justo e solidário diretamente com recursos públicos e utilizando as compras governamentais, bem como através da qualificação dos praticantes do comércio justo e solidário e até por financiamento dos agentes que tivessem necessidade. A finalidade de, construir esse sistema público teve também o objetivo criar um "sistema não excludente", que não deixasse de fora aqueles que não pudessem arcar com os custos da certificação.

Assim, o funcionamento do SCJS também está diretamente ligado à certificação, mas nela não se encerra. No Brasil, as organizações ligadas ao comércio justo e solidário estarão também ligadas à Economia Solidária, atuando diretamente na construção de uma agenda de política pública mais ampla para promover os Empreendimentos Econômicos e Solidários. A Portaria MPE n. 2060, de 2014, define tais empreendimentos como: empreendimento econômico solidário com prática em comércio justo e solidário; parceiro comercial com prática em em comércio justo e solidário, organismos de avaliação de conformidade; organizações da sociedade civil de apoio e fomento ao comércio justo e solidário; e parceiros públicos do em comércio justo e solidário.

Portaria MPE n. 2060, de 2014

Art. $4^{\circ}$ Os participantes do SCJS estão divididos nas seguintes categorias: 
I - empreendimento econômico solidário com prática em CJS (EES/CJS): a organização de caráter associativo que realiza atividade econômica, cujos participantes são trabalhadores e trabalhadoras do meio urbano ou rural que exercem democraticamente a gestão das atividades e a alocação dos resultados e que foi submetido a um processo de avaliação da conformidade da garantia reconhecido no âmbito do SCJS; II - parceiro comercial com prática em CJS (PC/CJS): a sociedade empresária, a sociedade simples, a empresa individual de responsabilidade limitada e o empresário de micro e pequeno porte a que se refere o art. $3^{\circ}$ da Lei $n^{\circ} 123$, de 14 de dezembro de 2006, que realizam ou prestam serviços na produção, beneficiamento, armazenamento, transporte, distribuição e comercialização (atacado ou varejo) dos produtos e serviços desenvolvidos e ou realizados por um EES-CJS; III - organismos de avaliação de conformidade: as organizações responsáveis por avaliar e reconhecer a conformidade dos EES e parceiros comerciais por meio de um conjunto de padrões estabelecidos em Sistema de Avaliação de Conformidade, de acordo com as modalidades reconhecidas no SCJS; IV - organizações da sociedade civil de apoio e fomento ao comércio justo e solidário: as organizações que desenvolvem ou ofertam serviços de apoio aos processos de produção, comercialização e consumo de empreendimentos econômicos solidários; e V parceiros públicos do CJS (PP/CJS): os municípios, os estados, o Distrito Federal e os órgãos da União que aderem ao SCJS.

A mesma portaria também apresenta definições importantes como o Cadastro Nacional de Empreendimentos Econômicos Solidários (CadSol); a Declaração de Empreendimento Econômico Solidário (DCSol); o Selo do CJS e o Certificado de Conformidade do Comércio Justo e Solidário (CERTSOL). Dentre as definições, a marca "ECOS"; a marca "Parceiro Comercial do SCJS” e preço justo.

Por meio dessas Portarias detalhadas e abrangentes do MPE percebe-se que o poder público capinaneou a construção do sistema de avaliação da conformidade do SCJS, estabelecendo o procedimento, os critérios e os princípios a serem observados pelos empreendimentos postulantes a serem reconhecidos como praticantes de comércio justo e solidário, e dessa forma se coloca como intermediário para a admissão desses empreendimentos no SCJS. Isso marca uma crucial diferenciação epistemológica em termos do que é praticado pelos entes privados que normalmente atuam no âmbito internacional. Mas apesar disso, a lógica da certificação foi mantida, espelhando a maioria do referencial teórico desenvolvido internacionalmente.

Nesse sentido, pôde-se observar que a construção do sistema de avaliação da conformidade do SCJS foi toda determinada pelo poder público, que estabeleceu, por meio de portarias ministeriais, o procedimento, os critérios e os princípios a serem observados pelos EES postulantes a serem reconhecidos como praticantes de CJS e portanto parte do SCJS. Nota-se que apesar da diferenciação em relação aos processos transnacionais no canal de comercialização (focado no mercado consumidor interno e não internacional) e na forma de enxergar a prática do comércio justo (a partir de uma visão mais de "princípios" do que "economicista"), a operacionalidade do SCJS passa por um método de avaliação de conformidade que resulta numa certificação e possibilidade de utilização de um Selo, como ocorre no âmbito transnacional. A novidade é que a política de fomento ao CJS passa pela "estratégia de política pública" de fomento à Ecosol, vez que eles foram realizados de maneira integrada por meio do Cadsol, que é mais amplo e engloba todos os EES cadastrados, além das diferentes metodologias de avaliação da conformidade 
reconhecidas pelo sistema, para além da avaliação da terceira parte praticada pela FLO. (PARK, 2015, p. 115)

Trata-se portanto de um transplante jurídico não integral mas negociado e adaptado pelos fatores específicos nacionais. O início da promoção do comércio justo no Brasil surgiu sob influência da FLO com a criação do Faces Brasil. A FLO já havia certificado produtores brasileiros independentemente da Faces antes disso. Mas a sua criação visou importar a prática de certificação elaborada pela FLO para o Brasil, como uma Iniciativa Nacional de certificação. Contudo, essa importação transfronteiriça de normas jurídicas, não foi absoluta, nem unidirecional. Foi influenciada pela tensão de objetivos e valores existentes nos níveis transnacional e local, sofreu, assim, apropriação e adaptação, processo no qual os diversos intermediários tiveram papel crucial na configuração do resultado, refletindo ambições dos movimentos sociais da Agricultura Familiar e da Economia Solidária.

Antes atores desses movimentos e veiculadores de suas demandas, passaram então a moldar o processo de adaptação segundo suas percepções de mundo aliando a proposta de comercialização justa pelo reforço e criação de canais para esses produtos acessarem o mercado consumidor com as demandas específicas de atender aos objetivos de comercialização existentes na Agricultura Familiar e na Economia Solidária. Além disso, incluíram na ideia de uma comercialização justa, facilitada pela certificação de produtos de acordo com determinados padrões, os estímulos à geração de renda e trabalho para agricultores e trabalhadores organizados em autogestão, valor central da Economia Solidária.

Outra peculiaridade foi que no Brasil houve a escolha pela regulamentação pública, diferentemente da prática transnacional, promovida somente por atores privados. Desde a formação do Faces Brasil o Estado já estava presente, por meio de representantes da SENAES (Ministério do Trabalho e Emprego) e da Secretaria de Agricultura Familiar (Ministério do Desenvolvimento Agrário). Possivelmente outra configuração de poder teria como resultado arranjos regulatórios distintos sobre a prática de comercialização justa, criando, por exemplo instâncias privadas de definição de padrões e princípios para certificação.

A principal inovação resultante desse caráter público da regulação foi a possibilidade de certificação de um produtor sem possibilidades de arcar com os custos do processo de conformidade, criando um "direito" para esse produtor ter esse serviço de certificação pago pelo Estado, gerando um tipo de assistência técnica solidária, garantindo a competitividade a esses pequenos produtores familiares, por meio da constatação de que a certificação serve como barreira ao acesso a mercados, sem ela os produtos são impedidos de alcançar seus nichos de mercado.

Nessa dialética de transplante de normas transnacionais para o âmbito nacional, pode ser que os termos e condições adotados internacionalmente sejam impactados pelas opções e conquistas conseguidas no Brasil. Quem sabe essa assistência técnica solidária não se torne modelo de exportação dos processos jurídicos transnacionais. Colocando o Brasil como articulador e influenciador de movimentos e organizações de outros países.

Muito tem sido feito para tornar o comércio transnacional mais aberto, justo, solidário e previsível, principalmente nos últimos 70 anos. No entanto, ainda se está muito aquém das necessidades de inclusão social da imensa maioria da população mundial na economia contemporânea. As negociações multilaterais estão travadas por impasses minoritários, assim, cada vez mais é vista como pouco eficiente, sendo inclusive marginalizada e estigmatizada contraproducente, pelos executivos operantes nas cadeias globais de valor, tanto das empresas grandes como de pequenas. O regionalismo e o bilateralismo que já tiveram o seu charme, estão no ostracismo.

Os avanços tecnológicos, principalmente na área de comunicação reestruturaram o comércio internacional. Barreiras regulatórias complexas e custos elevados de transação acabam 
penalizando principalmente as pequenas e médias empresas, consequentemente facilitando cada vez mais o oligopólio da cadeia global de valor por poucas e muito poderosas empresas ou conglomerados.

O setor de serviços, tem sido o que representa de longe o maior setor em ambos os países desenvolvidos e em desenvolvimento, e cuja participação está aumentando. Porém é o mais carente de normas multilaterais. Em muitos casos, o vácuo regulatório, tanto no setor de bens como de serviços vem sendo preenchido pelo estabelecimento de normas privadas. Apesar de apresentar algumas vantagens, como rapidez e efetividade, não é suficiente para substituir um maior envolvimento de organismos multilaterais e de órgãos dos governos, principalmente no tocante à meta regulação, para verificar se esses padrões privados estão sendo feitos da melhor maneira, seguindo os princípios democráticos, com transparência e cientificidade.

A menor atuação em foros multilaterais, tem como consequência o crescimento dos níveis de imprevisibilidade do comércio internacional, assim, os custos de financiamento tendem a subir e ficar restrito aqueles empreendedores que se comprometerem a buscar certificações que possam servir ao financiador como garantia de que melhores práticas foram cumpridas no tocante principalmente aos requisitos socioambientais.

Os vários agentes do comércio transnacional precisam entender esse novo contexto de governança multistakeholder, e se comprometer a reagir, se adequando aos padrões privados existentes, obtendo certificações e exigindo uma maior clareza com relação às normas sobre como devem ser feitos os padrões privados (metaregulação). Precisa ficar claro, principalmente para os agentes de política pública que as pequenas e médias empresas podem ser forçadas a sair do mercado internacional tendo em vista os altos custos de conformidade.

Talvez uma das alternativas possa ser a combinação pública e privada de governança que foi adotada na criação do SNCJS. A fim de criar assistência técnica solidária que possa garantindo a competitividade dos pequenos e médios produtores, para que esses não sejam expulsos da cadeia global de valor. Implementando formas de diminuir os custos de certificação, para os pequenos e médios produtores, diminuem as barreiras de acesso aos mercados trasnacionais, assim os produtos do comércio justo e solidário podem disputar com os grandes conglomerados um lugar nos nichos de mercado global. Fazendo assim, se está indiretamente fomentando o aumento da renda, o trabalho digno e a proteção ao meio ambiente.

\section{CONCLUSÕES}

O mundo precisa de comércio e investimento para impulsionar o crescimento e desenvolvimento. A atividade de comércio e investimento, por sua vez, resulta de uma grande quantidade de decisões comerciais individuais tomadas pelas empresas grandes e pequenas em todo o mundo. É um contexto difuso com diversos atores reflexivamente influenciando e sendo influenciado pelo conjunto. Conduzir esse conjunto de interesses para opções mais justas, solidárias e eficientes é um desafio.

A sustentabilidade é um caso marcante de "wicked problem" tão complexo que requer o envolvimento múltiplo das diversas partes interessadas para ser gerenciado. Porém iniciativas de ação coletiva, com várias partes interessadas, coordenando esforços em busca de objetivos comuns, não são simples de serem atingidas. Pelo contrário essa governança multistakeholder impõe desafios enormes de articulação de interesses muitas vezes opostos. Porém, problemas complexos não podem ser solucionados com respostas simples, assim, a questão da superação de obstáculos para a ação coletiva apesar de ser igualmente complexa, parece ser a única forma de apresentar resultados para o equilíbrio orquestral entre interesses sociais, econômicos e ambientais.

Nesse contexto os esquemas de padrões privados e certificação para produtos e fornecedores como praticantes do comércio justo e solidário, servem de ferramentas úteis para 
facilitar a sistematização e a análise dos mercados sustentáveis. Sendo assim, neste artigo foi abordada a organização interna e o processo que se seguiu para desenvolver e implementar o SNCJS, que foi muito além do esquema de certificação privado adotado internacionalmente.

Foi feito, ainda, um recorte histórico a fim de justificar alguns resultados ideológicos que ficaram imbricados na composição do modelo brasileiro. Evidenciando assim, um processo dialético entre o âmbito internacional e interno no tocante ao transplante jurídico de normas, o que ficou evidente na análise da importação dos padrões privados transnacionais e da certificação para o sistema nacional que o adaptou, adequou a sua realidade e poderá inclusive servir de modelo para outros países.

\section{REFERÊNCIAS}

BRASIL. Decreto 5.811, de 21 de junho de 2006. Dispõe sobre a composição, estruturação, competência e funcionamento do Conselho Nacional de Economia Solidária - CNES. Diário Oficial da União, Brasília, DF, 22 de jun. de 2006. Disponível em: http://www.planalto.gov.br/ccivil_03/_Ato2004-2006/2006/Decreto/D5811.htm >. Acesso em 10 de maio de 2016.

BRASIL. Decreto n.o 7.358, de 17.11.2010. Institui o Sistema Nacional do Comércio Justo e Solidário - SCJS, cria sua Comissão Gestora Nacional, e dá outras providências. Diário Oficial da União, Brasília, DF, 18 nov. de 2010. Disponível em: http://www.planalto.gov.br/ccivil_03/_ato2007-2010/2010/decreto/d7358.htm >. Acesso em 10 de maio de 2016.

BRASIL. Decreto no 5.063, de 3 de maio de 2004. Aprova a Estrutura Regimental e o Quadro Demonstrativo dos Cargos em Comissão e das Funções Gratificadas do Ministério do Trabalho e Emprego, e dá outras providências. Diário Oficial da União, Brasília, DF, 04 de maio de 2004. Disponível em: http://www.planalto.gov.br/ccivil_03/_ato2004-2006/2004/decreto/d5063.htm >. Acesso em 10 de maio de 2016.

BRASIL. Lei no 10.683, de 28 de maio de 2003. Dispõe sobre a organização da Presidência da República e dos Ministérios, e dá outras providências. Presidência da República. Diário Oficial da União, Brasília, DF, 29 de maio de 2003. Disponível em: http://www.planalto.gov.br/ccivil_03/leis/2003/110.683.htm >. Acesso em 10 de maio de 2016.

BRASIL. Portaria n.o 1.780 de 19.11.2014. Institui o Cadastro de Empreendimentos Econômicos Solidários - CADSOL. Ministério do Trabalho e Emprego. Diário Oficial da União, Brasília, 20 nov. 2014. Seção 1, pp. 78-79. Disponível em: http://www.planalto.gov.br/ccivil_03/leis/2003/110.683.htm >. Acesso em 10 de maio de 2016.

BRASIL. Portaria n.o 2060 de 30/12/2014. Institui os princípios, critérios, sistema de avaliação de conformidade e os mecanismos de gestão do Sistema Nacional de Comércio Justo e Solidário - SCJS. Ministério do Trabalho e Emprego. Diário Oficial da União, Brasília, DF, 08 jan. 2015. Disponível em: http://www.legisweb.com.br/legislacao/?id=279940 $>$. Acesso em 10 de maio de 2016. 
DADUSH, U. et al. What companies want form the Multilateral Trading System?, World Economic Forum. 2015.

DUPUY, Pierre Marie, VIÑUALES, Jorge E., Environmental Protection and International Economic Law, 2015

FACES DO BRASIL. Histórico. Rio de Janeiro. 2008. Disponível em: http://www.facesdobrasil.org.br/historico.html >. Acesso em 10 de maio de 2016.

FAIRTRADE INTERNATIONAL. Constitution of the Association. Maio 2007. Disponível em: http://www.fairtrade.net/fileadmin/user_upload/content/2009/about_fairtrade/2011-06-28_fairtrade-glossary_WFTO-FLO-FLOCERT.pdf >. Acesso em 10 de maio de 2016.

ONU. Transformando Nosso Mundo: a Agenda 2030 para o Desenvolvimento Sustentável. 2015. Disponível em < http://www.pnud.org.br/Docs/TransformandoNossoMundo.pdf > Acesso em 10 de maio de 2016.

OSTROM, Elinor. Governing the commons: The evolution of intitutions for collective action. Cambridge University Press, 2015

PARK, Christine Seung Hee. Processos Jurídicos Transnacionais e Transformações Estatais: $O$ Fair Trade e a Construção do Sistema de Comércio Justo e Solidário no Brasil FGV, 2015 Disponível em https://bibliotecadigital.fgv.br/dspace/bitstream/handle/10438/13721/Dissertação\%20Christine\% 20Park? sequence $=1 \&$ isAllowed $=\mathrm{y}>$ Acesso em 10 de maio de 2016.

STELZER, Joana; GONÇALVES, Everton. Da tripla dimensão do comércio mundial: multilateralismo, regionalismo e Fair Trade. In: ENCONTRO NACIONAL DO CONPEDI/UFSC, 2014. Florianópolis. Direito Internacional: XXIII Encontro Nacional do Conpedi. Florianópolis: CONPEDI, 2014. Disponível em: < http://www.publicadireito.com.br/artigos/?cod=cab8961422e0f17f $>$. Acesso em 10 de maio de 2016.

THORSTENSEN, Vera (2011). O Multissistema da Regulação do Comércio Internacional: Proposta de Novo Referencial Teórico e Nova Metodologia de Análise, in Revista Tempo do Mundo v.3, n.1, Brasília: IPEA

THORSTENSEN, Vera and VIEIRA, Andreia Costa, Are the Wolves of protectionism disguised under sheep skin?, Cambridge University Press, 2015

THORSTENSEN, Vera; VIEIRA, Andreia Costa, Private Standards or Market Standards: in search for legitimacy and accountability in the International Trading System, 2015

UNFSS Forum on Sustainability Standards, Geneva, 2013. Disponível em < www.unfss.org/ > Acesso em 10 de maio de 2016. 